\title{
A COMPLEMENTAÇÃO ANUAL DA UNIÃO AO FUNDEB E O CONSEQUENTE AJUSTE DE CONTAS: SE O LENÇOL PARECE CURTO, O CAMINHO É PEDIR COBERTOR EXTRA AO JUDICIÁRIO?
}

\section{THE ANNUAL COMPLEMENT OF THE FEDERATION TO FUNDEB AND ITS CONSEQUENT ACCOUNT ADJUSTMENT: TO ASK AN EXTRA COVER TO THE JUDICIARY POWER IS THE RIGHT WAY IF THE SHEETS SEEM SHORT?}

\section{DANUTA RAFAELA NOGUEIRA DE SOUZA CALAZANS}

Procuradora Federal (Advocacia-Geral da União - AGU). Atualmente é CoordenadoraGeral de Assuntos Internacionais e Judiciais do Ministério da Mulher, da Família e dos Direitos Humanos. Possui graduação em Direito e especialização em Direito Processual. Mestranda em Políticas Públicas, Estado e Desenvolvimento do Centro Universitário de Brasília (UniCEUB). Participante dos Grupos de Pesquisa Cortes Constitucionais e Democracia e Direito Ambiental e Desenvolvimento Sustentável (UniCEUB). Tem experiência profissional na área de Direito Público.

\section{MARCELO DIAS VARELLA}

Professor do Programa de Mestrado e Doutorado em Direito do Centro Universitário de Brasília desde 2002. Assessor Especial do Ministro da Economia. Doutor em Direito pela Universidade de Paris I, Panthéon-Sorbonne, com doutorado sanduíche na Universidade de Oxford. Livre-Docente em Direito pela USP. Pós-Doutorados nas Universidades da Califórnia? Berkeley, George Washington e Georgetown nos Estados Unidos. Foi advogado privado durante 10 anos e consultor em mais de 70 projetos, para diferentes organismos internacionais na América Latina e na Europa. Desde 2006, Especialista em Políticas Públicas e Gestão Governamental no Governo Federal, tendo sido Secretário Executivo do Ministério dos Direitos Humanos, 
Secretário de Assuntos Legislativos do Ministério da Justiça, assessor especial ou consultor jurídico em diferentes Ministérios. Como docente, lecionou em vários países, como França, Suíça, Estados Unidos, México, Argentina, e em cursos de formação e aperfeiçoamento para Magistratura, Ministério Público, Diplomatas, AGUs e Ciclo de Gestão Pública. Titulou 60 mestres e doutores em Direito.

\section{RESUMO}

Objetivo: Este artigo objetiva analisar a preocupante situação dos questionamentos ao Fundo de Manutenção e Desenvolvimento da Educação Básica e de Valorização dos Profissionais da Educação (FUNDEB) nas esferas estadual e municipal, que vêm conduzindo a uma sistemática subversão da ordem estabelecida, cujo rompimento revela-se gravoso para a manutenção e para a promoção do desenvolvimento da educação básica; bem como elaborar um estudo do potencial alcance das políticas públicas a serem implementadas a partir das receitas repartidas através do FUNDEB, e um exame sobre os riscos que as decisões oriundas do Poder Judiciário podem trazer à própria subsistência do mencionado Fundo, que foi instituído com vigência estabelecida para o período 2007-2020.

Metodologia: A metodologia deste trabalho prevê a análise histórica do Fundo, o estudo das prescrições legais - inclusive a partir das mudanças verificadas no texto da lei ao longo do tempo - para comprovar os imensos riscos gerados pelo sistemático, improdutivo e corriqueiro questionamento ao FUNDEB, bem como uma análise do texto constitucional e da legislação infraconstitucional que disciplinam o tema.

Resultados: A partir destas análises, é possível concluir que o atual arcabouço constitucional e legal que sustentam o FUNDEB são adequados para regular o funcionamento do mencionado Fundo, de forma que suas receitas vêm sendo operadas de maneira satisfatória nos últimos anos, possibilitando afirmar, portanto, que não cabem mais alterações sistemáticas ao funcionamento do FUNDEB, pois essas alterações atrapalham e eventualmente podem vir a inviabilizar o regular exercício dos objetivos aos quais esta reserva dirige-se.

Contribuições: A principal contribuição deste estudo é, portanto, a proposta - ao Poder Judiciário - da manutenção do status quo relativo ao FUNDEB, de forma a evitar a instabilidade oriunda das excessivas alterações nas suas prescrições legais.

PALAVRAS-CHAVE: FUNDEB; educação básica; complementação da união; ajuste. 


\begin{abstract}
Objective: To analyze the great concern related to the questionings addressed to the Fund for the Maintenance and Development of Basic Education and the Appreciation of Education Professionals (FUNDEB), at state and municipal levels, which have been leading to a systematic subversion of the established order, which rupture reveals burdensome to the maintenance and promotion of the development of basic education; as well as to elaborate a study of the potential reach of the public policies to be implemented from the proceeds shared through FUNDEB, and an examination of the risks that the decisions coming from the Judiciary can bring to the existence of FUNDEB, which was incorporated to be valid between 2007-2020.
\end{abstract}

Methodology: The methodology of this paper foresees the historical analysis of the Fund, the study of legal statutory requirements - including the changes in the text of the law over time - to prove the immense risks generated by the systematic, unproductive and routine questioning of FUNDEB, as well as an analysis of the constitutional text and the infra-constitutional legislation governing the subject.

Results: Based on these analysis, it is possible to conclude that the current constitutional and legal framework that supports FUNDEB are adequate to regulate the operation of the Fund, so that its revenues have been operating satisfactorily in recent years, making it possible to affirm, therefore, that no longer entails systematic changes to the functioning of FUNDEB, as these changes hinder and may eventually derail the regular exercise of the objectives to which this reserve is directed.

Contributions: The main contribution of this study is the proposal to the Judiciary to maintain the status quo related to FUNDEB, in order to avoid the instability arising from excessive changes in its legal statutory requirements.

KEYWORDS: FUNDEB; basic education; federal complement; adjustment.

\title{
INTRODUÇÃO
}

Apesar do Fundo de Manutenção e Desenvolvimento da Educação Básica e de Valorização dos Profissionais da Educação - FUNDEB ter sido criado pela Emenda Constitucional n 53/2006 e ter sua sistemática em pleno funcionamento há cerca 10 anos, nos últimos meses questionamentos que atentam contra a própria subsistência do Fundo vêm sendo feitos por vários estados e municípios brasileiros, recebendo, por diversas vezes, o aval do Poder Judiciário. A situação é preocupante e merece ser analisada, pois a cada tentativa de subversão da ordem e da sistemática 
constitucionalmente definidas, o FUNDEB é revisado, o que põe todos os entes federativos que recebem fatia das receitas do Fundo em situação de vulnerabilidade.

A prática vivenciada nos últimos anos demonstra que os critérios delineados pelo Constituinte Reformador de 2006 são suficientes para o funcionamento eficaz do FUNDEB, não havendo razões para o Judiciário acolher os infundados pleitos dos estados e municípios que visam, tão somente, aumentar injustamente o montante particular a ser recebido na repartição das receitas. Uma razão nada legitima que pode pôr em risco, em última análise, a qualidade da educação básica brasileira.

O FUNDEB é um fundo especial, de natureza contábil e de âmbito estadual, formado, na quase totalidade, por recursos provenientes dos impostos e transferências dos estados, Distrito Federal e municípios, vinculados à educação por força do disposto no art. 212 da Constituição Federal. Além desses recursos, ainda compõe o FUNDEB, a título de complementação, uma parcela de recursos federais, sempre que, no âmbito de cada estado, seu valor por aluno não alcançar o mínimo definido nacionalmente. A complementação realizada pela União e o ajuste anual previsto no art. $6^{\circ}$, parágrafo $2^{\circ}$ da Lei ํㅜ 11.494 de 2007 são os temas em evidência e que têm sofrido mais investidas e gerado maiores questionamentos perante Judiciário.

Para comprovar que os critérios e requisitos definidos pela $E C$ nํ53/2006 são suficientes para o regular e satisfatório funcionamento do FUNDEB, este texto propõe uma análise do texto constitucional e da legislação infraconstitucional que disciplinam o tema, um estudo do potencial alcance das políticas públicas a serem implementadas a partir das receitas repartidas através do Fundo, e um exame sobre os riscos que as decisões oriundas do Poder Judiciário podem trazer à própria subsistência do FUNDEB, que foi criado com vigência estabelecida para o período 2007-2020.

\section{FUNDEB: CONCEITO E UM POUCO DE HISTÓRIA}

O ordenamento jurídico brasileiro tem destinado especial tratamento ao direito à educação básica, por sua indiscutível importância na evolução individual e da 
sociedade.

É certo que o Brasil caminha para a universalização do nível básico de ensino. No entanto, pressuposto da difusão da educação de qualidade é a sua gratuidade, o que exige, por consequência, financiamento adequado, sendo este o principal problema político e econômico em termos de concretização do direito fundamental social à educação (FREITAS, 2009).

Assim, conhecer os mecanismos de financiamento da educação pública no Brasil, principalmente da educação infantil é uma forma de conscientização e politização fundamentais para o exercício da cidadania, entendida como a realização dos desejos do povo (MONLEVADE, 2001).

Observa-se uma evidente uma mudança de paradigma com relação à infância, que passou a ser o centro das atenções no que diz respeito aos interesses governamentais, o que fez com que a educação infantil passasse a ocupar lugar de destaque na sociedade. $E$, dentro deste contexto de valorização da infância, no que se refere às políticas públicas educacionais, foi criado, a partir do Fundo de Manutenção e Desenvolvimento do Ensino Fundamental e de Valorização do Magistério (FUNDEF), o Fundo de Manutenção e Desenvolvimento da Educação Básica e de Valorização dos Profissionais da Educação (FUNDEB) com o objetivo de proporcionar a elevação e uma nova distribuição dos investimentos em educação, realizando o atendimento não só ao ensino fundamental, como também à educação infantil, ao ensino médio e à educação de jovens e adultos (CALDEIRA, 2010).

O Fundo de Manutenção e Desenvolvimento da Educação Básica e Valorização dos Profissionais de Educação - FUNDEB foi criado pela Emenda Constitucional $n^{\circ}$ 53/2006 e regulamentado pela Lei no 11.494 de 20 de junho de 2007, sendo considerado um instrumento de vasta distribuição de recursos vinculados à educação básica do país, que reparte entre os entes governamentais recursos financeiros com base no número de alunos matriculados em seus sistemas de ensino, de acordo com os seus respectivos âmbitos de atuação prioritária. Trata-se de política publica definida constitucionalmente.

No entanto, para entender o funcionamento do FUNDEB, é imprescindível que seja feito, antes, um breve resgate histórico do FUNDEF, seu antecessor. 
O FUNDEF, Fundo de Manutenção e Desenvolvimento do Ensino Fundamental e de Valorização do Magistério, foi instituído pela Emenda Constitucional no 14 de 1996 e regulamentado pela Lei no 9.424, de 24 de dezembro de 1996. A maior inovação trazida pelo FUNDEF consistiu na mudança da estrutura de financiamento do ensino fundamental no país, ao subvincular a esse nível de ensino uma parcela dos recursos constitucionalmente destinados à educação. $A$ Constituição de 1988 vincula $25 \%$ das receitas dos estados e municípios à educação. Com a Emenda Constitucional no 14/96, 60\% desses recursos (o que representa 15\% da arrecadação global de estados e municípios) ficaram reservados ao ensino fundamental. Além disso, introduziram-se novos critérios de distribuição e utilização de $15 \%$ dos principais impostos de estados e municípios, promovendo a sua partilha de recursos entre o governo estadual e seus municípios, de acordo com o número de alunos atendidos em cada rede de ensino.

Inicialmente, o FUNDEF era criticado porque se considerava que não traria recursos significativos para a educação. Em segundo plano, criticava-se o privilégio dado à educação básica, a associação com arrecadação tributária, à queda da arrecadação (DAVIES, 2006). Contudo, a arrecadação foi expressiva. Para se ter uma ideia, no ano de 1998, entraram nos cofres do FUNDEF a título de contribuição dos estados e municípios $R \$ 12.934 .405 .549,19$, e mais $R \$ 434.819 .032,79$ sob a rubrica de complementação da União, se chegando numa receita total de $\mathrm{R} \$ 13.369 .224 .581,98$. Com a soma desses valores, o valor médio por aluno, naquele ano, foi de $\mathrm{R} \$ 423,50 .^{1}$

O FUNDEF é um exemplo de política pública com suporte constitucional, tendo se valido de expediente de alteração das Disposições Transitórias para, alterando o seu art. 60, passar a vincular as receitas da educação disciplinas no art. 212 do corpo constitucional, com vistas à universalização do atendimento à educação fundamental e à remuneração condigna do magistério, noutros termos, à melhoria das condições da prestação do direito à educação. (DALLARI BUCCI, 2006).

${ }^{1}$ Conforme tabela elaborada pelo Fundo Nacional de Desenvolvimento da Educação, constante do Anexo 1 
À época da alteração implementada pela Emenda Constitucional no 14/96, verificava-se um novo papel atribuído à União Federal de exercer, em matéria educacional, função redistributiva e supletiva, de forma a garantir equalização de oportunidade educacionais e padrão mínimo de qualidade do ensino mediante assistência técnica e financeira dos estados, DF e municípios.

Assim, o FUNDEF era um fundo de natureza contábil e de âmbito estadual, composto pela alíquota de 15\% dos seguintes impostos e transferências: FPM (Fundo de Participação Municipal), FPE (Fundo de Participação Estadual), ICMS (Imposto sobre Circulação de Mercadorias e prestação de Serviços), IPI Exportações (Imposto sobre Produtos Industrializados, proporcional às exportações) e LC № 87/96 (Lei Complementar no 87 de 1996 - Desoneração de Exportações). Além desses impostos e transferências, o Fundo também contava com uma parcela relativa à Complementação da União, que seria utilizada quando os estados, através de suas arrecadações, não conseguissem alcançar o valor do aluno por ano, nacionalmente definidos, através de decreto presidência. Como dito, o FUNDEF destinava-se exclusivamente ao ensino fundamental e vigorou de $1^{\circ}$ de janeiro de 1998 a 31 de dezembro de 2006.

O princípio básico do FUNDEF era o de disponibilizar um valor anual mínimo nacional por matrícula no ensino fundamental de cada rede municipal e estadual, de modo que possibilitasse o que o Governo Federal entendia como suficiente para um padrão mínimo de qualidade. Esse Fundo estabeleceu como objetivos centrais promover: 1) a justiça social; 2) uma política nacional de equidade; 3) a efetiva descentralização e a melhoria da qualidade da educação e 4) a valorização do magistério público (CALDEIRA, 2010).

$A$ avaliação dos impactos do FUNDEF levou à constituição de uma política mais abrangente, nascendo assim o FUNDEB, que passou a abarcar não apenas o ensino fundamental, mas toda a educação básica brasileira. Mesmo sendo tida por alguns como uma revolução, a constituição de um Fundo específico para a educação básica não pode deixar de ser encarada como uma continuidade da política de fundos instituída pela EC ํㅜㄴ 14/96 e pela Lei ำ 9.424/96, com alguns ajustes para permitir o seu aperfeiçoamento. 
Assim, o FUNDEB surge com o objetivo de permitir o aumento e implementar uma nova forma de distribuição dos investimentos em educação, proporcionando a garantia da educação básica a todos os brasileiros (da educação infantil, passando pelo ensino fundamental e chegando até o ensino médio), inclusive daqueles que não tiveram acesso à educação na idade adequada. À época do seu surgimento, a abrangência deste Fundo estendeu o atendimento de 32 milhões de alunos, até então beneficiados pelo FUNDEF, para 47 milhões de alunos matriculados na educação infantil, no ensino fundamental e médio das redes estaduais e municipais, em todas as modalidades e ensino, inclusive na educação de jovens e adultos (FERNANDES, 2004).

Desta feita, com a Emenda Constitucional ํㅡ 53/2006, a subvinculação das receitas dos impostos e transferências dos estados, Distrito Federal e municípios passou para $20 \%$ e sua utilização foi ampliada para toda a educação básica por meio do FUNDEB, que promove a distribuição dos recursos com base no número de alunos da educação básica informado no censo escolar do ano anterior, sendo computados os estudantes matriculados nos respectivos âmbitos de atuação prioritária (art. 211 da Constituição Federal). Ou seja, os municípios recebem os recursos do FUNDEB com base no número de alunos da educação infantil e do ensino fundamental, e os estados, com base nos alunos do ensino fundamental e médio.

O FUNDEB, tal qual o FUNDEF, é um fundo de natureza contábil e a sua composição, no âmbito de cada estado e do Distrito Federal, detalhada nos incisos I a IX do art. $3^{\circ}$ e nos $\S \S 1^{\circ}$ e $2^{\circ}$ da Lei o 11.494 de 2007, provém de uma cesta integrada por 20\% dos seguintes impostos e transferências constitucionais: ITCMD, ICMS, IPVA, ITRm, IPlexp, FPE, FPM, Impostos que a União eventualmente instituir no âmbito de sua competência, recursos relativos à Desoneração das Exportações (LC no 87/96), além da receita da dívida ativa tributária, juros e multas relativos às referidas receitas, bem como da Complementação da União, cujo objetivo é assegurar o valor mínimo nacional por aluno (VMAA) definido a cada ano aos estados (ou, se for o caso, ao Distrito Federal) que não conseguirem, com seus próprios recursos, atingir o valor mínimo. 
Os recursos do FUNDEB devem ser empregados exclusivamente em ações de manutenção e de desenvolvimento da educação básica pública, particularmente na valorização do magistério. Registre-se que parcela mínima de $60 \%$ do FUNDEB, calculada sobre o montante anual dos recursos creditados na conta no exercício, deve ser destinada à remuneração dos profissionais do magistério em efetivo exercício na educação básica pública,. Tais profissionais devem ter vínculo contratual em caráter permanente ou temporário com o estado, Distrito Federal ou município, regido tanto por regime jurídico específico do ente governamental contratante quanto pela Consolidação das Leis do Trabalho (CLT).

Cabe salientar que o objetivo dos preceitos constitucionais e legais que vinculam $60 \%$ dos recursos do FUNDEB à remuneração dos profissionais do magistério público da educação básica é, precipuamente, direcionar recursos que auxiliem na criação e implementação dos planos de carreira e no cumprimento do piso salarial do magistério. Assim, a essência das políticas públicas de valorização do magistério é garantir a esses profissionais uma melhor formação e condições de trabalho que estimulem o ingresso e permanência na carreira.

A arrecadação dos recursos que compõem o Fundo, ou seja, dos impostos e transferências constitucionais supramencionados, é realizada pela União e pelos Governos Estaduais, nos termos do art. 16, parágrafo único, Lei ํำ11.494 de 2007, sendo a disponibilização dos recursos gerados realizada periodicamente pelo Tesouro Nacional e pelos órgãos fazendários dos governos estaduais, ao Banco do Brasil, que procede à distribuição dos recursos mediante crédito em favor dos estados e municípios beneficiários (art. 17 da Lei nº 11.494 de 2007), em conta única e específica instituída para essa finalidade, no próprio Banco do Brasil ou na Caixa Econômica Federal.

Assim, os recursos do FUNDEB são distribuídos de forma automática e periódica, mediante crédito na conta especifica de cada governo estadual e municipal.

Hoje, muitos reconhecem o FUNDEB como o maior e mais abrangente mecanismo de financiamento da educação do país, com distribuição das receitas de impostos e transferências vinculados à educação básica, promovendo redução de desigualdades, equalização e garantia de valor mínimo por aluno/ano. A título de 
exemplo, a fim de permitir uma melhor compreensão sobre o seu tamanho e relevância, somente no ano de 2013, o Fundo recebeu $R \$ 108.276 .543 .978,11$ de contribuição dos estados e municípios e mais $R \$ 10.827 .654 .397,78$ de complementação da União, o que formou uma arrecadação total de $\mathrm{R} \$ 119.104 .198 .375,89$. O valor médio por aluno daquele ano foi de $R \$ 2.287,87$ considerando 41,9 milhões de matrículas da educação básica.

O FUNDEB teve importante efeitos na melhoria da qualidade do ensino. Em função das grandes assimetrias entre as escolas, a metodologia para distribuição dos recursos se mostrou positiva. Na disciplina de língua portuguesa, atribui-se ao FUNDEB a responsabilidade pelo efeito médio positivo de 12,1 pontos de acréscimo no rendimento escolar. Em matemática, 18,5 pontos. Contudo, a região com maior incremento foi o Sul do país, e não Norte ou Nordeste, como era de se esperar. Críticos argumentam que isso se deve a falta de capacidade financeira da União em contribuir com mais recursos para as regiões mais carentes (SILVEIRA, 2017)

Em resumo, O FUNDEB caracteriza-se como fundo especial, de natureza contábil e de âmbito estadual, formado por receitas específicas (art. $3^{\circ}$ da Lei 11.494 de 2007), vinculadas constitucionalmente ao Fundo (art. 60, inciso II, ADCT), com destinação voltada a objetivos determinados (art. 60, caput, ADCT c/c art. $2^{\circ}$ da Lei no 11.494 de 2007) e com normas próprias para a aplicação de seus recursos (art. 21 e 22 da Lei no 11.494 de 2007).

Justamente pela demora e face às dificuldades financeiras dos Estados e Municípios, houve a iniciativa do Congresso Nacional em discutir dois projetos de emenda constitucional para alterar o FUNDEB². O objetivo comum é constitucionalizar a Lei 12.858, perenizando o FUNDEB. Em ambos os projetos, há uma ampliação significativa e progressiva dos aportes da União, que poderiam chegar a $40 \%$ do total do fundo em alguns anos, ou seja, quadruplica o valor da participação da União.

Além dos aportes financeiros, as principais medidas são a inclusão no FUNDEB de $80 \%$ das receitas com exploração de minérios; a proibição do pagamento de aposentadorias e pensões com recursos dos fundos; a criação de obrigações para

2 PEC 15/2015, na Câmara dos Deputados e PEC 65/2019, no Senado Federal. 
os Estados e Municípios, como a participação da sociedade nos processos de formulação, monitoramento e controle das políticas. Ao contrário do defendido pelo Ministério da Educação, as propostas legislativas não vinculam os recursos às matrículas e sucesso dos alunos.

\section{A COMPLEMENTAÇÃO DA UNIÃO E O AJUSTE DE CONTAS ANUAL}

Uma das fontes adicionais de receita dos referidos Fundos decorre de repasses da União, conforme arts. $3^{\circ}$, $\S 2^{\circ}$ e $4^{\circ}$, da Lei no 11.494 de 2007 e 60, V, do ADCT.

Esses repasses são definidos na supramencionada lei como Complementação da União, que toma como base a estimativa de receitas a serem auferidas por estados, Distrito Federal e municípios no ano subsequente.

A previsão de complementação da União para o FUNDEB tem assento constitucional, nos seguintes termos:

Art. 60. Até o $14^{\circ}$ (décimo quarto) ano a partir da promulgação desta Emenda Constitucional, os estados, o Distrito Federal e os Municípios destinarão parte dos recursos a que se refere o caput do art. 212 da Constituição Federal à manutenção e desenvolvimento da educação básica e à remuneração condigna dos trabalhadores da educação, respeitadas as seguintes disposições: (Redação dada pela Emenda Constitucional no 53 , de 2006). (Vide Emenda Constitucional no 53, de 2006) (Vide Emenda Constitucional no 53, de 2006) I - a distribuição dos recursos e de responsabilidades entre o Distrito Federal, os Estados e seus Municípios é assegurada mediante a criação, no âmbito de cada Estado e do Distrito Federal, de um Fundo de Manutenção e Desenvolvimento da Educação Básica e de Valorização dos Profissionais da Educação - FUNDEB, de natureza contábil; (Incluído pela Emenda Constitucional nํ 53, de 2006). II os Fundos referidos no inciso I do caput deste artigo serão constituídos por $20 \%$ (vinte por cento) dos recursos a que se referem os incisos I, II e III do art. 155; o inciso II do caput do art. 157; os incisos II, III e IV do caput do art. 158; e as alíneas a e b do inciso I e o inciso II do caput do art. 159, todos da Constituição Federal, e distribuídos entre cada Estado e seus Municípios, proporcionalmente ao número de alunos das diversas etapas e modalidades da educação básica presencial, matriculados nas respectivas redes, nos respectivos âmbitos de atuação prioritária estabelecidos nos $\S \S 2^{\circ}$ e $3^{\circ}$ do art. 211 da Constituição Federal; (Incluído pela Emenda Constitucional no 53, de 2006). (...) V - a União complementará os recursos dos Fundos a que se refere o inciso II do caput deste artigo sempre que, no Distrito Federal e em 
cada Estado, o valor por aluno não alcançar o mínimo definido nacionalmente, fixado em observância ao disposto no inciso VII do caput deste artigo, vedada a utilização dos recursos a que se refere o $\S 5^{\circ}$ do art. 212 da Constituição Federal; (Incluído pela Emenda Constitucional ํㅡ 53, de 2006).

A matéria foi regulamentada pela Lei oㅜ 11.494, de 2007, que disciplinou não apenas o montante mínimo de complementação da União, mas também a maneira e o momento de sua realização e ainda a forma de cálculo do valor anual mínimo por aluno, nos seguintes termos:

Art. 4ㅇ A União complementará os recursos dos Fundos sempre que, no âmbito de cada Estado e no Distrito Federal, o valor médio ponderado por aluno, calculado na forma do Anexo desta Lei, não alcançar o mínimo definido nacionalmente, fixado de forma a que a complementação da União não seja inferior aos valores previstos no inciso VII do caput do art. 60 do ADCT. $\S$ 1ㅇ O valor anual mínimo por aluno definido nacionalmente constitui-se em valor de referência relativo aos anos iniciais do ensino fundamental urbano e será determinado contabilmente em função da complementação da União. § 2ㅇ O valor anual mínimo por aluno será definido nacionalmente, considerando-se a complementação da União após a dedução da parcela de que trata 0 art. $7^{\circ}$ desta Lei, relativa a programas direcionados para a melhoria da qualidade da educação básica. Art. 5o A complementação da União destina-se exclusivamente a assegurar recursos financeiros aos Fundos, aplicando-se o disposto no caput do art. 160 da Constituição Federal. § 1 o É vedada a utilização dos recursos oriundos da arrecadação da contribuição social do salário-educação a que se refere o $\S 50$ do art. 212 da Constituição Federal na da União aos Fundos. $\S 20$ A vinculação de recursos para manutenção e desenvolvimento do ensino estabelecida no art. 212 da Constituição Federal suportará, no máximo, 30\% (trinta por cento) da complementação da União. Art. 6o A complementação da União será de, no mínimo, 10\% (dez por cento) do total dos recursos a que se refere o inciso II do caput do art. 60 do ADCT. $\S 1$ A complementação da União observará o cronograma da programação financeira do Tesouro Nacional e contemplará pagamentos mensais de, no mínimo, 5\% (cinco por cento) da complementação anual, a serem realizados até o último dia útil de cada mês, assegurados os repasses de, no mínimo, $45 \%$ (quarenta e cinco por cento) até 31 de julho, de $85 \%$ (oitenta e cinco por cento) até 31 de dezembro de cada ano, e de $100 \%$ (cem por cento) até 31 de janeiro do exercício imediatamente subsequente. (...) 


\begin{tabular}{|c|l|}
\hline $\begin{array}{c}\text { Estados e } \\
\text { Distrito } \\
\text { Federal }\end{array}$ & $\begin{array}{l}20 \% \text { sobre: Quota estadual do ICMS; Quota estadual do IPVA; } \\
\text { Imposto sobre Transmissão Causa Mortis; Fundo de Participação } \\
\text { dos Estados; Quota estadual IPI-Exportação. }\end{array}$ \\
\hline Municípios & $\begin{array}{l}20 \% \text { sobre: Quota municipal do ICMS; Quota municipal do IPVA; } \\
\text { Quota municipal do ITR; Fundo de Participação dos Municípios }\end{array}$ \\
\hline União & $\begin{array}{l}\text { Complementa o valor do Fundeb com 9,5 bilhões nos 3 primeiros } \\
\text { anos, após os quais o valor da complementação passa a ser, no } \\
\text { mínimo, 10\% da contribuição dos estados e municípios. Pode } \\
\text { gastar até 10\% do valor de complementação para auxílio de } \\
\text { projetos }\end{array}$ \\
\hline
\end{tabular}

Fonte: BLIACHERIENE et. alii, 2016

Assim, os recursos da denominada "Cesta-FUNDEB" são complementados pela União, para assegurar o valor mínimo nacional por aluno (VMAA) definido a cada ano, aos estados (ou, se for o caso, ao Distrito Federal) que não conseguirem, com seus próprios recursos, atingir aquele valor mínimo. Porém, ao contrário do praticado na vigência do FUNDEF, no FUNDEB não se pode utilizar de recursos do salárioeducação para composição desta complementação, devendo, ainda, observar o teto de $30 \%$ para a fonte de manutenção e desenvolvimento do ensino (MDE). Estas medidas permitem preservar as fontes MDE e salário-educação, bem como atrair novos recursos para a complementação da União, a partir de outras fontes (MENDES, 2012). 


\begin{tabular}{|c|c|c|}
\hline Ano & $\begin{array}{c}\text { Complementação da } \\
\text { União (Bilhões de Reais) }\end{array}$ & Estados \\
\hline 2007 & 2,012 & AL, BA, CE, MA, PA, PB, PE, PI \\
\hline 2008 & 3,174 & AL, AM, BA, CE, MA, PA, PB, PE, PI \\
\hline 2009 & 5,071 & AL, AM, BA, CE, MA, PA, PB, PE, PI \\
\hline 2010 & 5,831 & AL, AM, BA, CE, MA, PA, PB, PE, PI \\
\hline 2011 & 9,328 & AL, AM, BA, CE, MA, PA, PB, PE, PI \\
\hline 2012 & 10,372 & AL, AM, BA, CE, MA, PA, PB, PE, PI \\
\hline 2013 & 9,180 & AL, AM, BA, CE, MA, PA, PB, PE, PI \\
\hline
\end{tabular}

Fonte: BLIACHERIENE et. alii, 2016

A Complementação da União foi objeto de ampla discussão no âmbito do FUNDEF, pois a participação do Governo Federal na composição do Fundo se dava mediante a complementação aos "fundos deficitários", isto é, aos fundos cujo valor por aluno fosse inferior ao valor mínimo nacional. Por esta razão tornava-se o único instrumento utilizado para a política de correção das desigualdades interestaduais, que constituía um dos objetivos estratégicos do fundo (VASQUES, 2005). Afirmavase, à época, que sem um considerável aporte de recurso por parte do Governo Federal, não haveria como viabilizar um sistema de financiamento que reduzisse as disparidades regionais e assegurasse um valor de recursos por aluno que garantisse um padrão mínimo de qualidade do ensino como estabelece a Constituição Federal e a Lei de Diretrizes e Bases da Educação Nacional (PINTO, 2004).

A polêmica continuou no FUNDEB, pois, quando do seu surgimento, muito se discutiu em virtude do fundo de educação básica não ter estabelecido mecanismos institucionais que assegurassem o cumprimento do efetivo por parte da União. Além disso, havia consenso em torno da necessidade de uma participação financeira mais efetiva e significativa do ente Federal.

Ao delinear o FUNDEB, a Constituição Federal estabeleceu limites mínimos para a complementação da União nos três primeiros anos de vigência e, a partir do quarto ano, fixou em $10 \%$ o valor da complementação em relação ao volume total dos 
recursos do Fundo.

Historicamente, desde então, e amparado no art. 6ํㅡ, caput da Lei $n^{\circ} 11.494$ de 2007, a União complementa anualmente o Fundo com 10\% do total dos recursos da "cesta-FUNDEB"3. Deste modo, na atual sistemática, a Complementação da União ao FUNDEB vem acontecendo de maneira satisfatória, sempre que no estado ou no DF o valor por aluno não alcançar o mínimo definido nacionalmente.

O ajuste de contas do FUNDEB - aqui simplesmente chamado de Ajuste por sua vez, surge como consequência à Complementação da União. Ao se comparar a estimativa de arrecadação informada pelos entes federativos e aquela efetivamente computada pelo Ministério da Educação e pelo Fundo Nacional de Desenvolvimento da Educação (FNDE) para um determinado ano, ajustes são realizados, no que diz respeito à necessidade de ter (ou não) havido a chamada Complementação pela União. A lógica é simples: caso a arrecadação efetiva seja maior do que a aquela estimada, os valores destinados aos estados e municípios a título de Complementação da União retornam ao FUNDEB para que sejam redistribuídos a outros entes federativos que necessitam daqueles recursos. Caso a arrecadação efetiva seja menor do que a arrecadação estimada, o ente federativo deve receber um crédito referente à Complementação pela União. É o que determina o §º do art. 6oㅜ da Lei no 11.194 de 2007:

Art. $6^{\circ}$. (...) $\S 2^{\circ} \mathrm{A}$ complementação da União a maior ou a menor em função da diferença entre a receita utilizada para o cálculo e a receita realizada do exercício de referência será ajustada no $1^{\circ}$ (primeiro) quadrimestre do exercício imediatamente subsequente e debitada ou creditada à conta específica dos Fundos, conforme o caso.

O Ajuste acontece não apenas com base no fundamento jurídico acima, mas também em razão de um fundamento fático, que decorre da metodologia de operacionalização do Fundo, já que o repasse dos recursos ocorre com base em mera estimativa de arrecadação dos impostos referidos no art. 3 da Lei no 11.494 de 2007.

\footnotetext{
${ }^{3}$ Por força de determinação contida no art. $6^{\circ}$, caput da Lei no 11.194 de 2007 a complementação da União será de, no mínimo, $10 \%$ (dez por cento) do total dos recursos a que se refere o inciso ll do caput do art. 60 do ADCT (Cesta-FUNDEB).
} 
Sendo assim, caso se verifique, após o encerramento do exercício, diferença a maior ou a menor entre a receita utilizada para o cálculo e aquela efetivamente realizada, procede-se ao acerto de contas quanto aos recursos repassados, debitando-se ou creditando-se, conforme o caso, as diferenças apuradas diretamente nas contas específicas do Fundo.

Ou seja, o ajuste de contas pode ser compreendido como um mecanismo legal e próprio do sistema jurídico do FUNDEB que permite corrigir a Complementação financeira que a União realiza em favor dos demais entes federativos que, por estimativa, não aparentariam conseguir alcançar o valor mínimo nacional de aplicação financeira por aluno matriculado num determinado ano, com base em suas previsões orçamentárias para aquele ano, as quais foram fixadas no ano anterior.

Apurados e consolidados os dados relativos aos valores disponibilizados e distribuídos ao longo do exercício, comparativamente aos valores calculados com base nas receitas efetivadas e devidos ao Fundo no mesmo exercício, é publicada Portaria Ministerial relativa ao ajuste anual, na qual são apontadas eventuais diferenças existentes, que devem ser disponibilizadas pelos governos estaduais, no âmbito dos vinte e sete fundos existentes no país.

$\mathrm{Na}$ dinâmica operacional do Fundo, os recursos (débitos) não retornam, em nenhuma hipótese, ao Governo Federal. Com a concretização do Ajuste, o que ocorre é a acomodação desses valores da Complementação da União entre estados em relação aos quais foi apurado crédito, de modo que o débito de uns é correspondente ao crédito de outros.

Aqui reside o risco de interpretação do ajuste do FUNDEB. O desconhecimento e a má compreensão do procedimento do Ajuste têm sido responsável pela parte mais expressiva das decisões liminares desfavoráveis à União. 


\section{OS RISCOS DECORRENTES DA NÃO REALIZAÇÃO DO AJUSTE E OS MOTIVOS PELOS QUAIS O JUDICIÁRIO NÃO DEVE INTERVIR NA SISTEMÁTICA DO FUNDEB}

Como visto, o FUNDEB foi inserido na Constituição em 2006 e, ao longo dos mais de 10 anos de vigência do Fundo, os entes federativos jamais se insurgiram contra o procedimento relativo ao Ajuste, seja administrativamente, seja judicialmente.

No ano de 2017, porém, a situação mudou e diversas ações judiciais foram propostas por estados e municípios com o único intuito de impedir a realização do Ajuste previsto no art. $6^{\circ}$, parágrafo $2^{\circ}$ da Lei o 11.494 de 2007. Citam-se, como exemplo, as Ações Cíveis Originárias números 3.001 e 3.005 em curso no STF ajuizadas pelos estados do Ceará e da Paraíba, respectivamente.

Ou seja, o procedimento, além de possuir claro fundamento legal, é do conhecimento dos entes envolvidos, que, todavia, decidiram, repentinamente, insurgirem-se ao verem-se prejudicados no acerto de contas realizado no exercício corrente. A alegação principal diz respeito à ausência de contraditório, afirmando-se que não foi dada oportunidade de manifestação aos entes antes da efetivação do Ajuste.

É o que ocorre, por exemplo, na ACO n. 3001, ajuizada em 27/04/2017, isto é, logo após a edição da Portaria MEC n. 565 de 20 de abril de 2017. Na ação, o Estado do Ceará alega em sua petição inicial que se encontrava na iminência de sofrer um desconto superior a $R \$ 160.000 .000,00$ nas contas estaduais do FUNDEB, referentes ao ajuste na complementação da União do exercício 2016 apurado como devido. Defende que o montante, calculado pela União e pelo FNDE como repassado a maior no exercício 2016, não deveria ser restituído sem prévia submissão à manifestação do Estado (contraditório e ampla defesa), pois, segundo acredita, não foi recebido de forma indevida. Narra que pelo contrário, foi recebido de boa-fé, conforme os parâmetros apurados pela própria Administração Federal.

Alega, ainda, que apesar de não desconhecer que a Lei n. ${ }^{0} 11.494 / 2007$ trata do ajuste necessário, a ser feito no primeiro quadrimestre de cada ano, para as hipóteses em que a complementação da União tenha sido superior ou inferior à 
devida, após ser conhecida, em janeiro de cada ano, essa previsão do Ajuste somente se aplicaria para as distorções pontuais entre a receita estimada e aquela efetivamente realizada. Não serviria para corrigir equívocos que ocasionem a reposição de grandes quantias, certamente decorrente de erro de premissa de cálculo e de omissão dos requeridos, mas não de frustração ou de superação da receita estimada.

Por tais motivos, requereu a inexigibilidade da restituição do montante entregue ao Estado, afirmando-o irrepetível e recebido de boa-fé, bem como sendoIhe garantido o exercício da ampla defesa e do contraditório antes de se proceder à compensação do débito, de uma só vez, pedindo, ainda, de forma subsidiária, o parcelamento em 240 (duzentos e quarenta) prestações mensais. Argumenta, ainda, que afrontaria o princípio da razoabilidade, da proporcionalidade e o próprio interesse público, a imposição da restituição em uma só parcela de valores repassados mensalmente durante todo um exercício.

Já na ACO n. 3.005, ajuizada em 11/05/2017, o Estado da Paraíba repete os mesmos fundamentos utilizados pelo Estado do Ceará na ACO n. 3.001, requerendo, do mesmo modo, a inexigibilidade da restituição do montante entregue ao Estado, por ser considerado irrepetível e recebido de boa-fé, e ainda que the seja garantido o exercício da ampla defesa e do contraditório antes de se proceder à compensação do débito de uma só vez, além de, subsidiariamente, requerer o parcelamento em 240 prestações mensais.

Na ACO n. 3.001, inicialmente foi deferida liminar pelo Ministro Luís Roberto Barroso, relator da ação, para que as rés se abstenham de deduzir dos valores destinados ao FUNDEB do Estado-autor o montante decorrente do ajuste previsto na Portaria MEC $n^{\circ}$ 565/2017, sem que se assegure oportunidade prévia de manifestação.

Posteriormente, em decorrência de agravos internos manejados pela União e pelo FNDE e diante da demonstração dos graves riscos ao funcionamento do Fundo, a liminar foi revogada nos seguintes termos: 
(...) 9. De acordo com o Anexo da Lei $n^{\circ} 11.494 / 2007$, o valor anual médio por aluno é definido após a distribuição dos recursos destacados pela União para complementação ao FUNDEB. Dessa forma, ao contrário do que ocorria no FUINDEF, os valores a serem repassados e ajustados no exercício financeiro seguinte não são influenciados pela metodologia de cálculo do VMAA. 10. Além disso, como a determinação do valor médio nacional por aluno resulta da distribuição da complementação da União, a suspensão do ajuste de contas previsto no art. $6^{\circ}$ da Lei $n^{\circ} 11.494 / 2007$ repercute sobre os demais Estados e Distrito Federal. Assim, entendo que o risco de dano inverso impõe a reconsideração da decisão liminar. 11. Diante do exposto, revogo a decisão liminar. Ficam prejudicados os agravos internos interpostos pela União e pelo FNDE.

Já na ACO n. 3.005, foi deferida a liminar pelo Ministro Relator Alexandre de Moraes, determinando à UNIÃO que se abstenha de deduzir, com relação ao autor, $O$ montante decorrente do ajuste previsto na Portaria MEC565/2017, até o julgamento final desta ação ou ulterior deliberação em sentido contrário. Diante de agravo com pedido de reconsideração, o Relator da ação, após a apreciação das informações apresentadas pela União, revogou a liminar pelos seguintes fundamentos:

(...) Sobrevieram no (sic) autos informações relevantes que modificam apercepção inicial sobre questão posta em análise. A União informa que "a manutenção da medida liminar pode gerar dano irreparável aos demais entes federados participantes do FUNDEB, ou seja, o dano resultante da concessão da medida é maior que aquele que se pretende evitar. (...) Assim, qualquer suspensão dos lançamentos do Ajuste de Contrato FUNDEB-2016, em relação à Paraíba, repercute inevitavelmente sobre os demais entes federados envolvidos no ajuste, por meio de débito para a compensação dos $\mathrm{R} \$ 35.187 .561,03$ não restituídos à conta do FUNDEB pela Paraíba (Estado + municípios). Isso porque os $\mathrm{R} \$ 35.187 .561,03$ não retornam aos cofres da União, mas são redistribuído (sic) sem favor dos entes federados credores do Ajuste de Contas do FUNDEB-2016. É dizer: eventuais liminares proferidas, conforme se pode observar no demonstrativo que segue em anexo, causam prejuízo em cadeia aos entes envolvidos no Ajuste do FUNDEB -2016, que encerraram o exercício com direito a créditos, por terem, recebido, com base em suas estimativas iniciais, complementação da União a menor" ( Petição 27.121/2017, fls. 6/7). Ante o exposto, revogo a medida liminar antes deferida. Intime-se o Estado da Paraíba sobre o pedido de reconsideração formulado pela União. Após, intime-se a União para oferecer contestação no prazo legal.

A concessão das liminares e posterior revogação diz muito sobre o caso em debate. É inquestionável a desnecessidade de contraditório, já que a Complementação da União é feita com base nas estimativas de receitas apresentadas pelos próprios entes e o Ajuste ocorre em razão da adequação desta estimativa à 
receita efetivamente arrecadada. Uma vez cientes do procedimento, afigurar-se-ia necessário o devido planejamento orçamentário, compatível com a dinâmica operacional do FUNDEB, do qual não podem escusar-se os estados, na condição de gestores dos recursos repassados por meio do Fundo (art. 69, $§ 5^{\circ}$, da Lei $n^{\circ} 9.394$ de 1996).

Já o argumento de que os valores teriam sido recebidos de boa-fé não poderia ser oposto à necessidade de participação no procedimento do Ajuste, uma vez que este se encontra previsto na Lei n. 11.494/2007 e era do conhecimento dos Estados do Ceará e da Paraíba, exemplos aqui citados, tampouco importando, assim, o fato de o ente governamental estadual ter aplicado corretamente os recursos, o que se configura como mera obrigação legal.

Aqui vale ser feita uma observação importante: da leitura das petições iniciais, nota-se que tanto o Estado do Ceará quanto o Estado da Paraíba não impugnam o valor do ajuste constante da Portaria MEC n. 565/2017. Pelo contrário, formulam pedido subsidiário de pagamento do valor do ajuste em 240 meses, caso haja a condenação neste sentido. Para tanto, relatam vivenciar grave crise financeira, o que não se constitui em fundamento para afastar o cumprimento das disposições legais, Tais pedidos evidenciam aquilo que este artigo pretende comprovar: a tentativa de alguns estados e municípios de afastar, diante da desorganização fiscal que enfrentam, a legislação de regência do FUNDEB e os deveres ali impostos através do manejo de ações perante o Judiciário.

Como dito anteriormente, em conformidade com a dinâmica operacional do ajuste de contas previsto no art. $6^{\circ}$, $\S 2^{\circ}$, da Lei no 11.494 de 2007, a Complementação da União, a maior ou a menor, apurada em função da diferença entre a receita utilizada para o cálculo e a receita realizada no exercício de referência, ocasiona débitos ou créditos, conforme o caso, à conta específica dos fundos. Logo, a cada ajuste de contas, pode vir a ser apurada a existência de débitos em desfavor de determinados entes governamentais (devedores) e de créditos em favor de outros (credores).

A questão sensível é que no procedimento do Ajuste de contas, o débito de uns representa o crédito de outros, visto que se trata de uma acomodação da Complementação da União, realizada após a apuração da arrecadação efetiva. 
Conforme visto, os recursos dos débitos do Ajuste não retornam ao Governo Federal. Assim, o prejuízo de discussões e eventuais liminares que suspendem o lançamento dos débitos recai, diretamente, sobre os entes governamentais credores nesse mesmo Ajuste.

Ou seja, além da Paraíba e do Ceará (e, consequentemente, seus municípios), a Bahia e o Maranhão também foram devedores do FUNDEB 2016. Por outro lado, Alagoas, Amapá, Pará, Pernambuco e Piauí possuindo valores a receber decorrentes do Ajuste de contas do FUNDEB neste ano e amargaram o atraso neste recebimento em decorrência da atuação daqueles que devem aportar recursos no Fundo.

Por essa razão, qualquer procedimento - em especial aqueles decorrentes de liminares proferidas pelo Poder Judiciário -, que venha a interferir nos cálculos operacionais do Ajuste de contas do FUNDEB causa repercussão nos demais entes federativos envolvidos nesse mesmo Ajuste. ${ }^{4}$ Ou seja, a atuação desses "agentes externos" acarreta consequências significativas tanto da perspectiva operacional quanto da legal, por ferir o disposto no art. 6으, § 2o, da Lei № 11.494 de 2007. E cada vez que o Judiciário defere uma liminar suspendendo o Ajuste, acaba por impedir que os estados e municípios credores recebam a sua "fatia" de receita referente ao Fundo, retardando assim, em última análise, a entrega de educação básica pública de qualidade e no momento adequado.

A suposta necessidade de exercício do contraditório pelos estados e municípios envolvidos no Ajuste de 2016, constitui, em verdade, tentativa de postergar a devolução dos recursos públicos recebidos a maior, uma vez que, conforme visto, o Ajuste de contas se dá mediante as informações fornecidas pelos próprios entes envolvidos. Caso o contraditório ocorresse, outra conclusão não existiria que não

\footnotetext{
${ }^{4}$ Um exemplo é o questionamento do Estado do Ceará em relação ao desconto realizado pela União de $R \$ 164,5$ milhões de reais, relativo aos valores não utilizados pelo Estado. O Ministro Luis Roberto Barroso garantiu o não desconto, na ACO 3001, de forma liminar, de modo a evitar prejuízos para a educação do Estado, quanto se aguarda o julgamento do mérito do processo. Contudo, a liminar foi revogada no mesmo processo, por concordar com os argumentos da União e não prejudicar os demais estados, que seriam afetados indiretamente. Ver STF. ACO 3001 DF, decisão monocrática do Min. Luis Roberto Barroso, de 31.05.2017
} 
aquela já encontrada, qual seja, a de que o ente tem saldo negativo após o Ajuste de constas.

O que ocorre na prática é nítida desorganização financeira e orçamentária dos estados e municípios, pois, mesmo sabendo que a arrecadação efetivamente alcançada não corresponde ao montante recebido a titulo de Complementação da União, decidem gastar os recursos recebidos a mais, o fazendo amparados na esperança de alcançar sucesso na tentativa de não devolução através de discussões no Judiciário. Em outras palavras, entendem que "compensa" não pagar a fatura, esperando que a Justiça os livre da obrigação de devolver valores que receberam a mais do que deveriam.

A coisa toda acontece da seguinte forma: os estados e municípios sabem, mês a mês, o valor de tributos por eles efetivamente arrecadados e devem fazer 0 batimento com a estimativa entregue ao Governo Federal. Caso a arrecadação supere o esperado, o valor recebido a maior a título de Complementação da União deverá ser devolvido no momento do Ajuste. Essa informação é de conhecimento geral, por estar expressa em Lei e por ocorrer ano após ano! Ocorre que alguns estados e/ou municípios, mesmo percebendo que terão que devolver considerável montante à União, continuam gastando indiscriminadamente, sem qualquer programação quanto à iminente devolução.

Tais atitudes são amparadas no argumento de que a Complementação da União seria pequena, insuficiente diante dos elevados custos que possuem com a manutenção e desenvolvimento da educação básica. Mesmo com uma participação do Governo Federal em forma de Complementação no valor de $\mathrm{R} \$ 12.973 .737 .185,18$ em 2017, os entes afirmam, que o lençol que a União os concede é curto para o tamanho da cama que precisam cobrir. $E$ por isso, decidem gastar indiscriminadamente, pedindo, em seguida, cobertor extra perante o Judiciário. E, apesar de toda a sistemática antes exposta, muitos conseguem alcançar o seu objetivo.

O que esses entes esquecem é que ao requerer judicialmente a não devolução do valor recebido a maior a titulo de Complementação da União não penalizam o Governo Federal, ente teoricamente mais rico, mas sim os demais 
estados e municípios credores do Fundo. Estes, cientes do real tamanho do lençol que os cobre, são mais organizados e estruturados para dispender os recursos repassados pela União, mas acabam sendo penalizados quando uma liminar é deferida em favor de outro ente que não se preparou adequadamente.

Assim, as decisões liminares que adiam o ajuste implicam, inegavelmente, na impossibilidade de redistribuição dos valores percebidos a maior pelos entes "devedores", prejudicando os estados e municípios que teriam direito a crédito, em razão do mencionado Ajuste, já que, conforme visto, a sistemática do FUNDEB impõe operação casada de debito e credito, não havendo sobras a compensar eventual retenção de recursos.

Em resumo, o Ajuste de Contas do FUNDEB caracteriza-se como procedimento operacional inerente à natureza das receitas que integram o Fundo, uma vez que, sendo estas provenientes de impostos e transferências constitucionais, acrescidos, posteriormente, da Complementação da União, mostra-se necessário, ao final de cada exercício, a realização de um batimento entre a receita efetivada (oriunda da arrecadação, de fato) e aquela que serviu de base para os cálculos operacionais (receita prevista). Não deve, por tais motivos, o Judiciário atender a pedidos que visem suspender a sistemática legalmente definida, seja por ser legítima ou porque conta com a ampla participação dos entes envolvidos, seja porque, ao deferir pedidos de suspensão do ajuste, penaliza estados e municípios indubitavelmente mais organizados do ponto de vista financeiro e orçamentário, que, por tais motivos, contam com os recursos que devem entrar em suas contas consoante disposição constitucional.

Vale mencionar que dois anos após o seu ajuizamento, a ACO n. 3.001 ainda não foi julgada, estando suspensa em razão da submissão da lide à Câmara de Conciliação e Arbitragem da Administração Federal - CCAF. Já a ACO n. 3.005 foi julgada improcedente em 13/03/2019, destacando-se o seguinte trecho da decisão do Relator, Ministro Alexandre de Moraes:

(...) Em nada modifica o quadro ora retratado a tese de que teria o autor, ao receber as receitas fruto da complementação da União no ano de 2016, agido de boa-fé. Se de fato é possível reconhecer que o autor manteve postura 
proba no ato de recebimento da complementação da União, direcionando-a à educação básica, em seus vários segmentos, também é de se esperar dele, por dever de coerência e cooperação, a normal sujeição ao ajuste de contas, com a consequente restituição de quantia recebida a maior, quanto mais porque dela poderia ter se beneficiado se, ao final, fosse apurado saldo positivo a seu favor. Trata-se de aplicação da boa-fé objetiva a todas as etapas previstas na já retratada sistemática do FUNDEB. Também não aproveita ao autor a invocação, a seu favor, do princípio da proporcionalidade ao argumento de que o valor a ser restituído, por ser vultoso, seria desproporcional às obrigações a serem cumpridas pelo estado membro nas esferas da edução (sic) básica. Como já realçado, a sistemática do FUNDEB vem toda estruturada no necessário equilíbrio da distribuição das receitas públicas entre os vários entes da federação, suprindo, assim, eventuais desigualdades e dificuldades na realização da educação básica nas mais diversas regiões do país. Exatamente por isso que, em prestígio ao invocado princípio da proporcionalidade, se projetou o ajuste de contas dos valores recebidos da União a título de complementação, frise-se, por estimativa, quando diversa a receita efetivamente realizada durante o mesmo exercício. Com isso se possibilita, no exercício seguinte, a distribuição mais igualitária dos recursos, direcionando-se a ente federado que recebeu quantia menor do que a devida a justa complementação. Ante o exposto, com fundamento no art. $21, \S 1^{\circ}$, do Regimento Interno do Supremo Tribunal Federal, JULGO IMPROCEDENTE A AÇÃO.

Apesar da interposição de Agravo interno, o Plenário do STF manteve a decisão de improcedência tal qual acima descrita. Assim, ao menos na ACO n. 3.005, ao que parece, o Supremo esteve atento às obrigações dos entes federativos no que tange à sua organização financeira e orçamentária, decidindo por determinar o cumprimento ao Ajuste tal qual definido pela legislação de regência do FUNDEB. Resta saber se o comportamento será reproduzido pelo Judiciário em momentos futuros, pois, por certo, novas tentativas de afronta da sistemática legal serão manejadas pelos entes federativos (estados e municípios) sempre que o equilíbrio das suas contas estiver em risco.

\section{CONCLUSÃO}

$O$ arcabouço constitucional e legal que alicerça o FUNDEB tem se demonstrado suficiente para permitir o adequado funcionamento do Fundo. A Complementação da União é feita historicamente a contento, após os reparos realizados a partir das críticas originalmente feitas quando da existência do FUNDEF 
e o Ajuste de Contas é necessário para liquidar eventuais diferenças entre a receita utilizada para o cálculo e aquela efetivamente realizada.

Sendo certo que o Fundo vem operando de maneira satisfatória nos últimos anos, o Judiciário não deve atender a pleitos de alteração da sistemática do FUNDEB. Tais pedidos, quando admitidos, além de terem o potencial de criar discriminações equivocadas, acabam por atrasar toda a distribuição dos recursos que transitam pelo Fundo.

No que tange ao Ajuste, este é indispensável não apenas por ter amparo legal, mas por gerar justiça entre os entes recebedores dos valores originários do Fundo. Caso o Ajuste seja suspenso para alguns estados e/ou municípios, outros acabam pagando a conta. A fatura repise-se, não chega para o Governo Federal, mas para aqueles entes que foram diligentes e programados financeiramente no que diz respeito ao FUNDEB.

Assim, cabe ao Judiciário negar os pedidos que visem interferir nos cálculos operacionais do Ajuste de contas do FUNDEB, para evitar repercussão negativa nos demais entes federativos envolvidos, em benefício de alguns poucos que visam, em última análise, aumentar injustamente o montante particular a ser recebido na repartição das receitas.

\section{REFERÊNCIAS}

AMORIM, Erica Pereira. O esquema de financiamento da Educação Básica no Brasil (1998 a 2007): Atribuições e responsabilidades, fontes e distribuição dos recursos e sistema de incentivos na transição FUNDEF-FUNDEB. Dissertação de Mestrado. Rio de Janeiro, 2007.

BLIACHERIENE et. alii, Decentralização do FUNDEB e federalismo da política educacional: uma análise à luz do conceito de accountability in Jornal de Políticas Educacionais, v. 10, n. 20, 2016.

BRASIL. Emenda Constitucional n. 14, de 12 de setembro de 1996. Modifica os artigos 34, 208, 211 e 212 da Constituição Federal e dá nova redação ao art. 60 do Ato das Disposições Constitucionais Transitórias. Disponível em: <www.planalto.gov.br>. Acesso em: 20 de julho de 2017. 
. Emenda Constitucional n. 53, de 19 de dezembro de 2006. Dá nova redação aos arts. $7^{\circ}, 23,30,206,208,211,212$ da Constituição Federal, e ao art. 60 do Ato das Disposições Constitucionais Transitórias. Disponível em: <www.planalto.gov.br>. Acesso em: 20 de julho de 2017.

Lei n. 11.494, de 20 de junho de 2007 (Lei do Fundeb). Regulamenta o Fundo de Manutenção e Desenvolvimento da Educação Básica e de Valorização dos Profissionais da Educação - FUNDEB. Disponível em: <www.planalto.gov.br>. Acesso em: 20 de julho de 2017.

Supremo Tribunal Federal. Disponível em http://portal.stf.jus.br/. Acesso em 02 de novembro de 2019.

BUCCI, Maria Paula Dallari. Políticas Públicas. Reflexões sobre o conceito jurídico. São Paulo: Saraiva, 2016.

CALDEIRA, Laura Bianca. Contribuições do Fundeb às Instituições de Educação Infantil de Montes Claros/MG. Dissertação de pós-graduação stricto sensu. Belo Horizonte, 2010.

DAVIES, N. FUNDEB: A redenção da educação básica. Educ. Soc, Campinas, v. 27, n. 96 - especial, p. 753-774, 2006.

FNDE. Perguntas Frequentes - FUNDEB. Disponível em < http://www.fnde.gov.br/financiamento/fundeb/perguntas-frequentes-fundeb $>$. Acesso em 19 de julho de 2017.

FERNANDES, Francisco das Chagas. Fundo de Manutenção e Desenvolvimento da Educação Básica - FUNDEB. In: COELHO, Rita de Cássia; BARRETO, Ângela Rabelo. (Orgs) Financiamento da Educação Infantil: perspectivas em debate. Brasília: UNESCO, 2004.

FREITAS, Aline da Silva. O Direito à Educação Básica no Brasil e o Problema do seu Financiamento. Dissertação de pós-graduação stricto sensu. São Paulo, 2009.

MACHADO, Maria Goreti Farias. A proposta de FUNDEB do executivo federal: interlocuções na formulação da política. Dissertação de Mestrado. Porto Alegre, 2007.

MENDES, Danielle Cristina de Brito. FUNDEB: avanços e limites no financiamento da educação básica no Brasil. São Carlos: Revista Eletrônica de Educação, 2012. Disponível em http://www.reveduc.ufscar.br. Acesso em 01 de agosto de 2017.

MONLEVADE, João Antônio Cabral de. Educação Pública no Brasil: Contos \& De\$contos. 2.ed. Ceilândia: Idea, 2001.

MONLEVADE, João Antônio Cabral de. O Fundo de Educação Básica e o 
Financiamento da Educação Infantil. In: COELHO, Rita de Cássia; BARRETO, Ângela Rabelo. Financiamento da Educação Infantil: perspectivas em debate. Brasília: UNESCO, 2004.

MONLEVADE, João Antônio Cabral de; FERREIRA, Eduardo B. O FUNDEF e seus Pecados Capitais: análise do Fundo, suas implicações positivas e negativas e estratégias de superação de seus limites 2.ed. Ceilândia: Idea, 1998.

MONLEVADE, João Antônio Cabral de. Para entender o FUNDEB. Ceilândia: Idea, 2007.

SILVEIRA; et al. Avaliação do efeito do FUNDEB sobre o desempenho dos alunos do ensino médio no Brasil in Pesquisa e Planejamento Econômico, v. 47, n. 1, 2017

ANEXO 1

\begin{tabular}{|c|c|c|c|c|}
\hline \multicolumn{7}{|c|}{ FUNDEF E FUNDEB - 1998 A 2017 } \\
\hline FUNDEF & $\begin{array}{c}\text { Contribuições de } \\
\text { Estados e } \\
\text { Municípios }\end{array}$ & $\begin{array}{c}\text { Complementação } \\
\text { da União }\end{array}$ & Receita Total & $\begin{array}{c}\text { Valor } \\
\text { Médio por } \\
\text { aluno }\end{array}$ \\
\hline $\mathbf{1 9 9 8}$ & $12.934 .405 .549,19$ & $434.819 .032,79$ & $13.369 .224 .581,98$ & 423,59 \\
\hline $\mathbf{1 9 9 9}$ & $14.839 .636 .850,09$ & $675.060 .919,96$ & $15.514 .697 .770,05$ & 458,30 \\
\hline $\mathbf{2 0 0 0}$ & $17.355 .814 .184,74$ & $505.636 .636,00$ & $17.861 .450 .820,74$ & 517,68 \\
\hline $\mathbf{2 0 0 1}$ & $19.736 .611 .697,78$ & $451.941 .279,00$ & $20.188 .552 .976,78$ & 592,79 \\
\hline $\mathbf{2 0 0 2}$ & $22.821 .638 .716,26$ & $421.804 .264,00$ & $23.243 .442 .980,26$ & 694,57 \\
\hline $\mathbf{2 0 0 3}$ & $25.164 .342 .194,97$ & $335.745 .800,00$ & $25.500 .087 .994,97$ & 769,66 \\
\hline $\mathbf{2 0 0 4}$ & $28.499 .008 .572,61$ & $484.996 .003,13$ & $28.984 .004 .575,74$ & 892,37 \\
\hline $\mathbf{2 0 0 5}$ & $32.789 .870 .733,55$ & $395.262 .616,87$ & $33.185 .133 .350,42$ & $1.038,91$ \\
\hline $\mathbf{2 0 0 6}$ & $36.164 .288 .886,38$ & $313.700 .235,00$ & $36.477 .989 .121,38$ & $1.165,32$ \\
\hline & Contribuições de & Complementação & Receita Total & $\begin{array}{c}\text { Valor } \\
\text { Mínimo } \\
\text { por aluno }\end{array}$ \\
\hline $\mathbf{2 0 0 7}$ & Muntados e & da União (100\%) & & 941,68 \\
\hline $\mathbf{2 0 0 8}$ & $61.721 .922 .188,69$ & $3.174 .300 .000,00$ & $64.896 .222 .188,69$ & $1.172,85$ \\
\hline $\mathbf{2 0 0 9}$ & $68.887 .808 .271,95$ & $5.070 .150 .000,00$ & $73.957 .958 .271,95$ & $1.227,17$ \\
\hline $\mathbf{2 0 1 0}$ & $79.458 .000 .618,68$ & $7.945 .800 .061,87$ & $87.403 .800 .680,55$ & $1.529,97$ \\
\hline $\mathbf{2 0 1 1}$ & $90.843 .108 .348,76$ & $9.084 .310 .834,88$ & $99.927 .419 .183,64$ & $1.846,56$ \\
\hline $\mathbf{2 0 1 2}$ & $97.837 .281 .712,22$ & $9.783 .728 .171,19$ & $107.621 .009 .883,41$ & $2.020,79$ \\
\hline $\mathbf{2 0 1 3}$ & $108.276 .543 .978,11$ & $10.827 .654 .397,78$ & $119.104 .198 .375,89$ & $2.287,87$ \\
\hline $\mathbf{2 0 1 4}$ & $115.545 .917 .762,16$ & $11.554 .591 .776,20$ & $127.100 .509 .538,36$ & $2.476,37$ \\
\hline $\mathbf{2 0 1 5}$ & $120.849 .982 .253,11$ & $12.084 .998 .225,29$ & $132.934 .980 .478,40$ & $2.627,08$ \\
\hline $\mathbf{2 0 1 6}$ & $128.767 .515 .868,90$ & $12.876 .751 .586,87$ & $141.644 .267 .455,77$ & $2.925,52$ \\
\hline $\mathbf{2 0 1 7}$ & $129.737 .371 .851,80$ & $12.973 .737 .185,18$ & $142.711 .109 .036,98$ & $2.875,03$ \\
\hline & & & & \\
\hline & & & & \\
\hline
\end{tabular}

